\title{
POLE and POLD1 pathogenic variants in the proofreading domain in papillary thyroid cancer
}

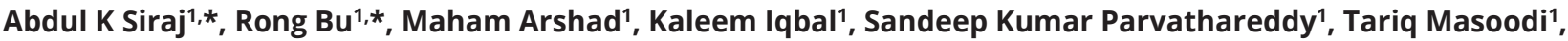 \\ Laila Omar Ghazwani', Saif S AI-Sobhi², Fouad Al-Dayel ${ }^{3}$ and Khawla S Al-Kuraya ${ }^{1}$ \\ ${ }^{1}$ Human Cancer Genomic Research, Research Centre, King Faisal Specialist Hospital and Research Centre, Riyadh, Saudi Arabia \\ ${ }^{2}$ Department of Surgery, King Faisal Specialist Hospital and Research Centre, Riyadh, Saudi Arabia \\ ${ }^{3}$ Department of Pathology and Laboratory Medicine, King Faisal Specialist Hospital and Research Centre, Riyadh, Saudi Arabia
}

Correspondence should be addressed to K S Al-Kuraya: kkuraya@kfshrc.edu.sa

*(A K Siraj and R Bu contributed equally to this work)

\begin{abstract}
Thyroid cancer is the most frequent endocrine cancer with an increasing incidence rate worldwide and is the second most common malignancy among females in Saudi Arabia. Papillary thyroid cancer (PTC) is the most common subtype. Germline pathogenic variants in the proofreading domain of the POLE and POLD1 genes predispose to several types of cancers. However, the role of pathogenic variants of these two genes in PTC remains unknown. Capture sequencing, Sanger sequencing and immunohistochemistry were performed on 300 PTC cases from the Middle Eastern region. One germline pathogenic variant each of POLE $(1 / 300,0.33 \%)$ and POLD1 (1/300, 0.33\%) genes was identified. Low expression of POLD1 was detected in $46.5 \%(133 / 286)$ of cases and was significantly associated with the follicular variant of PTC $(P=0.0006)$, distant metastasis $(P=0.0033)$ and stage IV tumours $(P=0.0081)$. However, no somatic pathogenic variant was detected in POLE gene. Furthermore, low expression of POLE was noted in $61.7 \%(175 / 284)$ of cases with no significant clinicopathological associations. Our study shows that pathogenic variant in the POLE and POLD1 proofreading domain is a cause of PTC and low expression of POLD1 is associated with poor prognostic markers in the Middle Eastern population. Further studies from different geographic populations are needed to determine the frequency and spectrum of proofreading domain pathogenic variants in POLE and POLD1 genes and in PTC from different ethnicities.
\end{abstract}

\section{Introduction}

Thyroid cancer is the most frequently occurring endocrine cancer with an increasing incidence rate worldwide and with a frequency among the younger age group $(1,2)$. It is also the second most common malignancy, after breast cancer, among females in Saudi Arabia, with a significantly higher incidence rate when compared to other countries, such as the USA $(2,3)$. Amongst the different subtypes, papillary thyroid cancer (PTC) is the most common and accounts for $80-90 \%$ of all thyroid cancers (4). PTC is well differentiated and curable with thyroidectomy (often followed by radioiodine treatment); however, the clinical behaviour of PTC varies widely and many patients suffer disease recurrence $(5,6)$. Although differentiated PTC is usually sporadic, cases of the familial form that is thought to be more aggressive in nature have also been reported $(7,8)$.

Faithful DNA replication and error control are imperative for the maintenance of genomic stability and repression of mutagenesis (9). The acquisition and accumulation of deleterious mutations can trigger

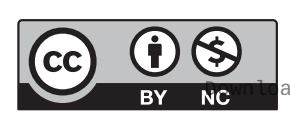

This work is licensed under a Creative Commons Attribution-NonCommercial 4.0 International License. ded from Bioscientifica.com at 04/26/2023 04:09:14AM 
carcinogenesis; therefore, a rigorous system to regulate DNA synthesis is essential. There are multiple mechanisms in place to ensure accurate replication of DNA; these include highly selective integration of nucleotides in the daughter strand; exonucleolytic proofreading to remove mismatched nucleotides; and post-replication mismatch repair (MMR) $(10,11)$. The fidelity of eukaryotic DNA replication is primarily governed by the DNA polymerases $\varepsilon$ (Pol $\varepsilon$ ) and $\delta(\mathrm{Pol} \delta)$; the catalytic and proofreading domains of which are encoded by POLE and POLD1, respectively (10). The leading strand of the replication fork is synthesised by Pol $\varepsilon$ whilst Okazaki fragments of the lagging strand are synthesised by Pol $\delta$ (in tandem with DNA polymerase $\alpha$ ). Both polymerases have an error rate of $\sim 10^{-4}$ to $10^{-5}$ which is further reduced to $\sim 10^{-9}$ to $10^{-10}$ via proofreading at the $3^{\prime}-5^{\prime}$ exonuclease domain as well as post-replication repair by the MMR apparatus ( 9 , 10, 11, 12).

Given that several mutations are needed for tumourigenesis, and DNA replication is extremely meticulous, it can be postulated that mutant polymerases and erroneous DNA synthesis play a key role in cancer development. Indeed, studies have reported an increase in the rate of spontaneous mutations in yeast and mice harbouring mutations in the $3^{\prime}-5^{\prime}$ exonuclease domain of Pol $\varepsilon$ and Pol $\delta(13,14,15)$. Furthermore, inactivation of the proofreading domain by a point mutation (POLD1 Asp400Ala) has been shown to increase the rate of oncogenesis in a recessive manner in mice $(16,17)$. Similarly, studies in humans using whole-genome and targeted sequencing have identified germline pathogenic variants in the exonuclease domain of POLE and POLD1 which predispose, with a high penetrance, to multiple and/or large colorectal adenomas, early-onset colorectal cancer (CRC) as well as endometrial cancer in female carriers $(18,19,20)$. In addition, somatic pathogenic variants of POLE have also been identified in different types of cancers with various incidence previously, most commonly reported in endometrial cancer (up to $10 \%$ ) $(19,21,22)$, followed by CRC $(3-4 \%)(23,24)$. However, among 560 PTC cases characterised by TCGA, only one case harboured POLE somatic pathogenic variant (25).

Whilst the effect of mutant POLE and POLD1 on susceptibility to colorectal cancer and endometrial cancer has been widely reported in the literature; the role of POLE and POLD1 in PTC remains unknown. Identification of genetic risk factors can help with screening and early detection and have important implications with respect to genetic counselling and implementation of treatment guidelines.
In our study, we investigated the prevalence and clinical relevance of germline and somatic variants in $P O L E$ and POLD1 proofreading domain and their protein expression in PTC cases from the Middle Eastern region.

\section{Materials and methods}

\section{Sample selection}

Archival samples from 300 PTC patients diagnosed at King Faisal Specialist Hospital and Research Centre (Riyadh, Saudi Arabia) between 1999 and 2013 were included in the study. Detailed clinicopathological data were noted from case records and have been summarised in Table 1 . All samples were obtained from patients with approval from the Institutional Review Board of the hospital. For the study, waiver of consent was obtained for archived paraffin tissue blocks from Research Advisory Council (RAC) under project RAC \# 2110031.

\section{DNA extraction}

DNAs were isolated from formalin-fixed, paraffinembedded (FFPE) PTC tumour and corresponding nontumour tissues using Gentra DNA isolation kit (Gentra, Minneapolis, MN, USA) following the manufacturer's recommendations as described previously $(26,27)$.

\section{PCR and Sanger sequencing for detection of germline and somatic variants in the proofreading domain of POLE and POLD1 genes}

Initially, direct sequencing of the entire coding/splicing region of the proofreading domains of POLE and POLD1 genes was performed on DNA samples from 50 cases both at somatic and germline level. Primer 3 software was used to design the primers for all coding exons and their flanking intronic sequences of proofreading domain of POLE and POLD1 genes (available upon request). PCR was performed in a total volume of $25 \mu \mathrm{L}$ using $20 \mathrm{ng}$ of genomic DNA, $2.5 \mu \mathrm{L}$ 10X Taq buffer, $2.3 \mathrm{mM} \mathrm{MgCl}_{2}, 0.2 \mathrm{mM}$ dNTPs, 1 unit Taq polymerase (all reagents were from Qiagen Inc), $0.2 \mu \mathrm{M}$ of each primer, and water. The efficiency and quality of the amplified PCR products were confirmed by running the PCR products on a $2 \%$ agarose gel.

For Sanger sequencing, the PCR products were subsequently subjected to direct sequencing with BigDye terminator $\mathrm{V} 3.1$ cycle sequencing reagents and analysed on an ABI 3730XL DNA analyser (Applied Biosystems). The reference sequence was downloaded from NCBI

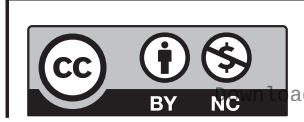

This work is licensed under a Creative Commons Attribution-NonCommercial 4.0 International License. ded from Bioscientifica.com at 04/26/2023 04:09:14AM 
Table 1 Clinicopathological variables for the patient cohort $(n=300)$.

\begin{tabular}{|c|c|}
\hline & $\boldsymbol{n}(\%)$ \\
\hline \multicolumn{2}{|l|}{ Age } \\
\hline Median & 39.0 \\
\hline Range (IQR) & $29.0-50.0$ \\
\hline \multicolumn{2}{|l|}{ Gender } \\
\hline Female & $233(77.7)$ \\
\hline Male & $67(22.3)$ \\
\hline \multicolumn{2}{|l|}{ Histopathology } \\
\hline Classical variant & $145(48.4)$ \\
\hline Follicular variant & $60(20.0)$ \\
\hline Tall cell variant & $43(14.3)$ \\
\hline Others & $52(17.3)$ \\
\hline \multicolumn{2}{|c|}{ Extra-thyroidal extension } \\
\hline Absent & $172(57.3)$ \\
\hline Present & $118(39.4)$ \\
\hline Unknown & $10(3.3)$ \\
\hline \multicolumn{2}{|l|}{ pT } \\
\hline T1 & $89(29.7)$ \\
\hline $\mathrm{T} 2$ & $60(20.0)$ \\
\hline T3 & $131(43.7)$ \\
\hline T4 & $18(6.0)$ \\
\hline Unknown & $2(0.6)$ \\
\hline \multicolumn{2}{|l|}{ pN } \\
\hline NO & $175(58.3)$ \\
\hline N1 & $122(40.7)$ \\
\hline Unknown & $3(1.0)$ \\
\hline \multicolumn{2}{|l|}{$\mathrm{pM}$} \\
\hline MO & $286(95.4)$ \\
\hline M1 & $13(4.3)$ \\
\hline Unknown & $1(0.3)$ \\
\hline \multicolumn{2}{|l|}{ Stage } \\
\hline I & 205 (68.3) \\
\hline II & $20(6.7)$ \\
\hline III & $42(14.0)$ \\
\hline IV & $31(10.4)$ \\
\hline Unknown & $2(0.6)$ \\
\hline
\end{tabular}

IQR, Interquartile range.

GenBank. Sequencing results were compared with the reference sequence by Mutation Surveyor V4.04 (Soft Genetics, LLC, State College, PA, USA).

\section{Whole exome sequencing of germline and somatic mutations in the proofreading domain of POLE and POLD1 genes}

Furthermore, whole exome sequencing (WES) was performed on 250 PTC cases as described previously (28). The tumour and corresponding normal DNA samples with A260/A280 ratio between 1.8 and 2.0 were processed for library construction. The sequencing library was prepared by random fragmentation of the DNA, followed by $5^{\prime}$ and $3^{\prime}$ adapter ligation. Adapter-ligated fragments were then PCR amplified and gel purified. Clusters were generated by loading the library into a flow cell where fragments were captured on a lawn of surface-bound oligos complementary to the library adapters. Each fragment was then amplified into distinct, clonal clusters through bridge amplification. Raw data was generated utilising HCS (HiSeq control software v3.3) and RTA (real-time analysis. v2.5.2).

The BCL (base calls) generated by Illumina Hiseq 4000 were converted into FASTQ files by bcl2fastq (v2.16). The sequence reads in fastq format from each sample were aligned to the reference human genome (GRCh37/hg19) using Burrows-Wheeler aligner (BWA) (29). BAM file generation, PCR duplicates and local realignment was performed using Picard-tools and genome analysis toolkit (GATK) (30).

The variant calling was performed by GATK, subsequently, the variants were annotated by ANNOVAR (31), with dbSNP138, 1000 Genomes, ESP6500, Exome Aggregation Consortium (ExAC), Clinvar and other genome databases. The variants detected by WES were further confirmed by Sanger sequencing.

\section{Assessment of pathogenicity of variants}

ACMG/AMP 2015 guideline was utilised first for interpretation of sequence variants. All the uncertain significant variants by ACMG/AMP 2015 guideline were further analysed using five in silico pathogenicity prediction tools: CADD, MutationAssessor, PolyPhen-2, SIFT and Mutation Taster (32). The variants predicted as damaging or possibly damaging by three or more in silico prediction tools were classified as potentially pathogenic variant and further investigated.

\section{Tissue microarray construction and immunohistochemistry}

All samples were analysed in a tissue microarray (TMA) format. TMA construction was performed as described earlier (33). Briefly, tissue cylinders with a diameter of 0.6 $\mathrm{mm}$ were punched from representative tumour regions of each donor tissue block and brought into a recipient paraffin block using a modified semiautomatic robotic precision instrument (Beecher Instruments, Woodland, WI). Two cores of PTC were arrayed from each case.

Standard protocol was followed for IHC staining. For antigen retrieval, Dako (Dako Denmark A/S) Target Retrieval Solution pH 9.0 (Catalog number S2367) was used, and the slides were placed in a Pascal pressure cooker for $8 \mathrm{~min}$ at $1200^{\circ} \mathrm{C}$. The slides were then incubated with primary antibodies against POLE

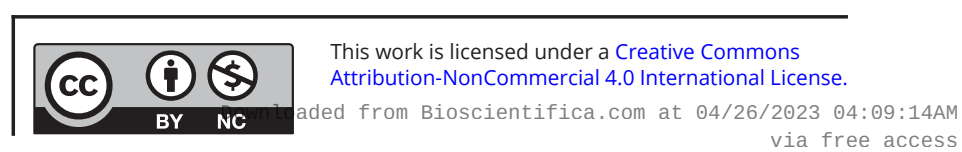


(ab-134941, Abcam) and POLD1 (ab-186407, Abcam) at a dilution of 1:1000 ( $\mathrm{pH}$ 9.0). The Dako Envision Plus System kit was used as the secondary detection system with 3,3'-diaminobenzidine as chromogen. All slides were counterstained with haematoxylin, dehydrated, cleared and mounted. Negative controls included omission of the primary antibody. Normal tissues of different organ system were also included in the TMA to serve as control. An array of normal thyroid tissue $(n=242)$ was also stained. Only fresh cut slides were stained simultaneously to minimise the influence of slide ageing and maximise the reproducibility of the experiment.

Scoring and interpretation were performed as described previously (34). Briefly, each TMA spot was assigned an intensity score from 0 to 3 (IO-I3) corresponding to no, weak, moderate and strong staining, and the proportion of tumour staining for that intensity was recorded as 5\% increments from a range of 0 to 100 (P0-P3). A final $\mathrm{H}$ score (range, 0-300) was obtained by adding the products of scores obtained for each intensity and proportion of area stained $(\mathrm{H}$ score $=\mathrm{I} 1 \mathrm{XP} 1+\mathrm{I} 2 \mathrm{xP} 2+\mathrm{I} 3 \times \mathrm{P} 3)$. Using X-tile version 3.6.1 (35), we defined the optimal cut-off point for POLE and POLD1 expression as $H=130$ and $H=125$, respectively. Based on $\mathrm{H}$ scores, PTC cases were classified into two subgroups: those below the cut-off score were defined as low expression, whereas those above the cut-off score were defined as overexpression.

Staining and evaluation of mismatch repair proteins (MLH1, MSH2, MSH6 and PMS2) were performed as described previously (36).

\section{Statistical analysis}

Contingency table analysis and Chi square tests were used to study the relationship between clinicopathological variables and protein expression. Disease-free survival curves were generated using the Kaplan-Meier method, with significance evaluated using the Mantel-Cox logrank test. The limit of significance for all analyses was defined as $P$ value of $<0.05$; two-sided tests were used in these calculations. The JMP11.0 (SAS Institute, Inc., Cary, NC, USA) software package was used for data analyses.

\section{Results}

\section{Sample characteristics}

A total of 300 unselected PTC cases were included in the study cohort. Majority of the patients were females

$(77.7 \%)$ and had the classical variant of PTC (48.4\%). $68.3 \%$ of patients had stage I tumour and $4.3 \%$ of patients had distant metastasis (Table 1).

\section{Identification of germline and somatic variants in proofreading domain of POLE and POLD1 genes}

Initially, we performed Sanger sequencing of 50 PTC samples to look for germline and somatic mutations in proofreading domain of POLE and POLD1 genes. We found one germline variant (c.1370C>T: p.Thr457Met) of the POLE gene which was interpreted as of uncertain significance by ACMG/AMP 2015 guideline. Further analysis showed that this variant was potentially pathogenic as predicted by three out of five in silico pathogenicity prediction tools. To further analyse the frequency of POLE and POLD1 pathogenic variants in PTC, we expanded our study to include another 250 PTC cases, which were analysed by WES. In this cohort of 250 cases, one germline variant (c.1006C>T:p. Gln336Ter) of POLD1 gene was detected and interpreted as pathogenic by ACMG/AMP 2015 guideline. However, no pathogenic variants were identified at somatic level in our cohort. Altogether, two germline variants (0.66\%), one pathogenic and one potentially pathogenic, were identified in the entire cohort of 300 PTC cases.

The POLD1 p. Gln336Ter heterozygous pathogenic variant was detected in a 36-year-old female who had a mixed classical and follicular PTC. The tumour was stage I with no extra-thyroidal extension. The POLE p.Thr457Met heterozygous variant was identified in an early-onset PTC patient (diagnosed at age of 18 years). The patient with POLE p.Thr457Met variant had stage I classical variant of PTC. This variant is conserved in four out of six species and absent in the population database of ExAC (Table 2). Both the cases were MMR proficient by immunohistochemistry.

Since germline mutations in the proofreading domains of POLE and POLD1 are associated with an increased risk

Table 2 Characteristics of POLE p.Thr457Met identified.

Gene

Mutation

PolyPhen-2

Mutation assessor

SIFT

CADD

Mutation taster

Family history

Conservation between species

Age at diagnosis

Frequency in ExAC

\section{POLE}

c.1370C>T: p Thr457Met Probably damaging Low

Tolerated

25.1

Disease causing

Negative

4 out of 6

18

Absent 

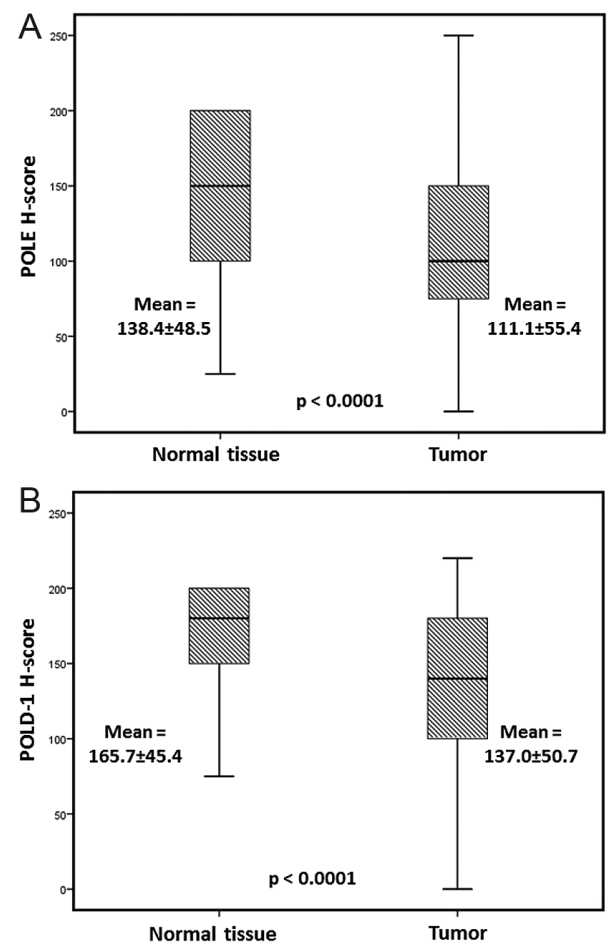

Figure 1

Boxplot showing difference in expression between normal and tumour tissue for POLE and POLD1. (A) POLE expression was significantly higher in normal tissue compared to tumour (mean $138.4 \pm 48.5$ vs $111.1 \pm 55.4$; $P<0.0001$ ). (B) POLD1 expression was significantly higher in normal tissue compared to tumour (mean $165.7 \pm 45.4$ vs $137.0 \pm 50.7$; $P<0.0001)$. of colorectal cancer, endometrial cancer and giant cell glioblastoma $(37,38,39)$, we looked for the co-existence of these malignancies in our cohort. One patient had developed rectal cancer prior to PTC, whereas another patient had endometrial cancer before developing PTC. However, neither of these patients harboured pathogenic variants of POLE or POLD1.

\section{POLE and POLD1 expression in PTC and their association with clinicopathological features}

Next, we evaluated the expression of POLE and POLD1 by immunohistochemistry in 300 PTC cases and 242 normal thyroid tissues using tissue microarray. The tumour tissues showed a significantly lower expression of POLE and POLD1 proteins compared to normal thyroid tissue (Fig. 1). POLE immunohistochemical expression was interpretable in 284 cases. Low expression of POLE was noted in $61.7 \%(175 / 284)$ of cases (Fig. 2A and B). No significant clinicopathological associations were noted (Table 3). The single POLE mutant case also showed low expression of POLE by IHC. POLD1 expression was interpretable in 286 cases. Low expression of POLD1 was noted in 46.5\% (133/286) of cases (Fig. 2C and D) and was significantly associated with the follicular variant of PTC $(P=0.0006)$, distant metastasis $(P=0.0033)$ and stage IV tumours $(P=0.0081)$ (Table 4$)$. The POLD1 mutant case showed over-expression of POLD1 protein. Both POLE

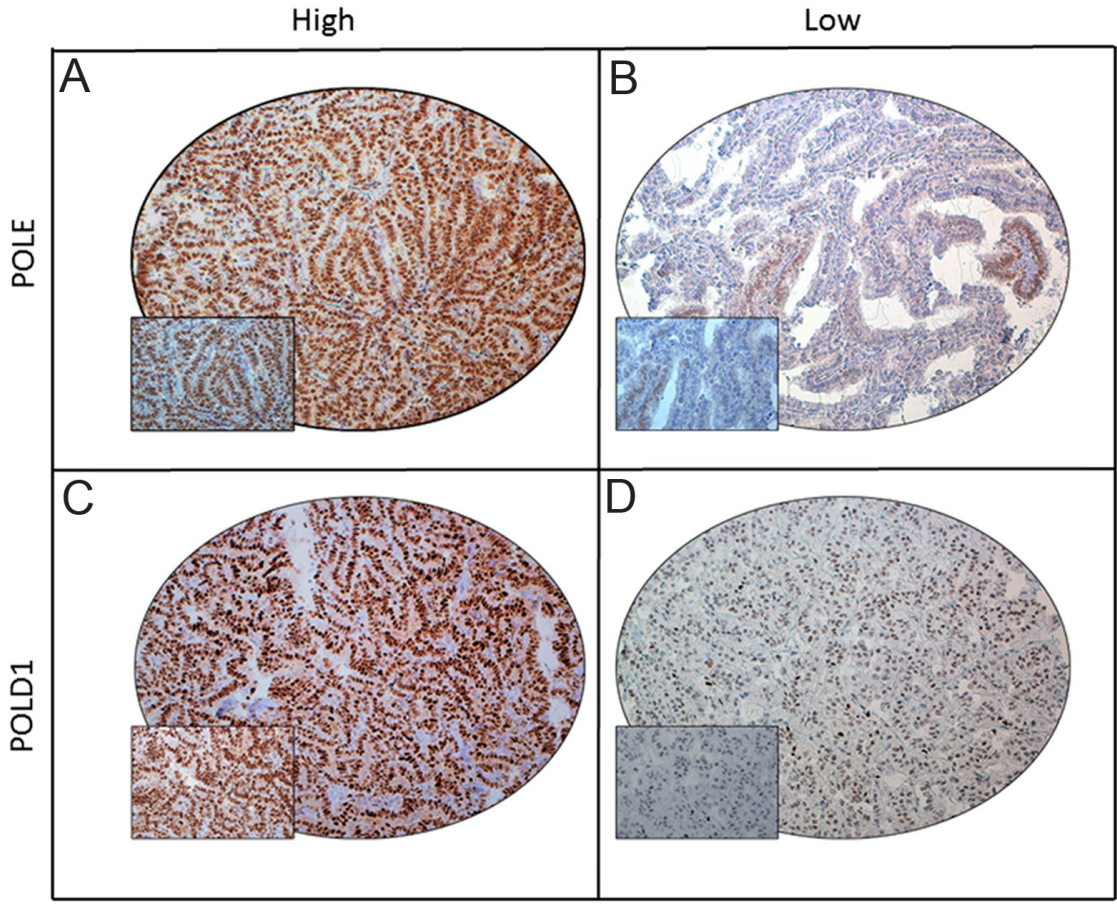

Figure 2

Tissue microarray-based immunohistochemistry analysis of POLE and POLD1 in PTC patients. PTC TMA spots showing overexpression of POLE (A) and POLD1 (C). In contrast, another set of TMA spots showing reduced expression of POLE (B) and POLD1 (D). 20X/0.70 objective on an Olympus BX 51 microscope with the inset showing a 40X/0.85 aperture magnified view of the same TMA spot. https://ec.bioscientifica.com https://doi.org/10.1530/EC-20-0258 (c) 2020 The authors Published by Bioscientifica Ltd

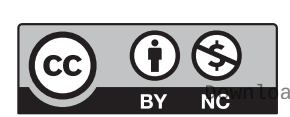

This work is licensed under a Creative Commons Attribution-NonCommercial 4.0 International License. ded from Bioscientifica.com at 04/26/2023 04:09:14AM via free access 
Table 3 Clinicopathological associations of POLE protein expression in papillary thyroid carcinoma.

\begin{tabular}{|c|c|c|c|c|c|c|c|}
\hline & \multicolumn{2}{|c|}{ Total } & \multicolumn{2}{|c|}{ POLE overexpression } & \multicolumn{2}{|c|}{ POLE low expression } & \multirow[b]{2}{*}{$P$ value } \\
\hline & No. & $\%$ & No. & $\%$ & No. & $\%$ & \\
\hline No. of patients & 284 & & 109 & 38.3 & 175 & 61.7 & \\
\hline \multicolumn{8}{|l|}{ Age (years) } \\
\hline$\leq 45$ & 176 & 62.2 & 67 & 38.1 & 109 & 61.9 & 0.8427 \\
\hline$>45$ & 107 & 37.8 & 42 & 39.3 & 65 & 60.7 & \\
\hline \multicolumn{8}{|l|}{ Sex } \\
\hline Female & 222 & 78.2 & 91 & 41.0 & 131 & 59.0 & 0.0825 \\
\hline Male & 62 & 21.8 & 18 & 29.0 & 44 & 71.0 & \\
\hline \multicolumn{8}{|c|}{ Extra-thyroidal extension } \\
\hline Absent & 164 & 59.6 & 60 & 36.6 & 104 & 63.4 & 0.4175 \\
\hline Present & 111 & 40.4 & 46 & 41.4 & 65 & 58.6 & \\
\hline \multicolumn{8}{|l|}{ pT } \\
\hline $\mathrm{T} 1$ & 85 & 30.1 & 27 & 31.8 & 58 & 68.2 & 0.2926 \\
\hline $\mathrm{T} 2$ & 58 & 20.6 & 24 & 41.4 & 34 & 58.6 & \\
\hline T3 & 122 & 43.3 & 53 & 43.4 & 69 & 56.6 & \\
\hline T4 & 17 & 6.0 & 5 & 29.4 & 12 & 70.6 & \\
\hline \multicolumn{8}{|l|}{$\mathrm{pN}$} \\
\hline pNO & 166 & 59.1 & 65 & 39.2 & 101 & 60.8 & 0.7647 \\
\hline $\mathrm{pN} 1$ & 115 & 40.9 & 43 & 37.4 & 72 & 62.6 & \\
\hline \multicolumn{8}{|l|}{$\mathrm{pM}$} \\
\hline pM0 & 272 & 96.1 & 107 & 39.3 & 165 & 60.7 & 0.1364 \\
\hline pM1 & 11 & 3.9 & 2 & 18.2 & 9 & 81.8 & \\
\hline \multicolumn{8}{|l|}{ Stage } \\
\hline 1 & 195 & 69.1 & 73 & 37.4 & 122 & 62.6 & 0.2346 \\
\hline ॥ & 17 & 6.0 & 5 & 29.4 & 12 & 70.6 & \\
\hline III & 40 & 14.2 & 21 & 52.5 & 19 & 47.5 & \\
\hline IV & 30 & 10.7 & 10 & 33.3 & 20 & 66.7 & \\
\hline \multicolumn{8}{|l|}{ Histology type } \\
\hline Classical variant & 137 & 48.2 & 49 & 35.8 & 88 & 64.2 & 0.5692 \\
\hline Follicular variant & 58 & 20.5 & 22 & 37.9 & 36 & 62.1 & \\
\hline Tall-cell variant & 43 & 15.1 & 16 & 38.1 & 27 & 61.9 & \\
\hline Other variants & 46 & 16.2 & 22 & 47.8 & 24 & 52.2 & \\
\hline \multicolumn{8}{|l|}{ Disease-free survival } \\
\hline 5 years & & & & 84.3 & & 76.4 & 0.1590 \\
\hline
\end{tabular}

and POLD1 protein expression were not associated with disease-free survival $(P=0.1590$ and 0.5197 , respectively; Fig. 3).

\section{Discussion}

During the past decades, there has been a significant increase in the incidence of PTC worldwide $(1,2,3$, 4). Hence, further research is necessary to identify the cellular and genetic changes which trigger oncogenesis in order to administer appropriate targeted therapies as well as improve the prevention and assessment of cancer risk. Knowledge of mutation distribution can also be used to plan cost-effective genetic testing strategies on a national scale.

Pathogenic variants of the proofreading domains in POLE and POLD1 genes are widely known to be associated with different cancers including endometrial

$\begin{array}{lr}\text { https://ec.bioscientifica.com } & \text { ( ) } 2020 \text { The authors } \\ \text { https://doi.org/10.1530/EC-20-0258 } & \text { Published by Bioscientifica Ltd }\end{array}$

cancer, colorectal cancer, lung cancer, and glioblastoma $(19,22,24,39,40,41,42,43,44)$. However, there are very limited current literature regarding these variants in PTC, with TCGA reporting only a single POLE somatic pathogenic variant among 560 cases (25). To the best of our knowledge, we are the first to report the frequency of proofreading domain germline pathogenic variant of the POLE and POLD1 genes in PTC cases. In our cohort, one pathogenic variant in the proofreading domain of POLD1 and one potentially pathogenic variant in the proofreading domain of POLE were identified, accounting for $0.66 \%$ of all PTC cases. Interestingly, these two variants were not reported previously. The variant of POLD1 p. Gln336Ter caused a stop gain and was identified in an early onset patient, indicating a functional loss and predisposition to PTC. Although the POLE p.Thr457Met variant was classified as uncertain significance by ACMG, it was partially conserved and completely absent in the population database of ExAC. 
Table 4 Clinicopathological associations of POLD1 protein expression in papillary thyroid carcinoma.

\begin{tabular}{|c|c|c|c|c|c|c|c|}
\hline & \multicolumn{2}{|c|}{ Total } & \multicolumn{2}{|c|}{ POLD1 overexpression } & \multicolumn{2}{|c|}{ POLD1 low expression } & \multirow[b]{2}{*}{$P$ value } \\
\hline & No. & $\%$ & No. & $\%$ & No. & $\%$ & \\
\hline No. of patients & 286 & & 153 & 53.5 & 133 & 46.5 & \\
\hline \multicolumn{8}{|l|}{ Age (years) } \\
\hline$\leq 45$ & 179 & 62.8 & 102 & 57.0 & 77 & 43.0 & 0.1085 \\
\hline$>45$ & 106 & 37.2 & 50 & 47.2 & 56 & 52.8 & \\
\hline \multicolumn{8}{|l|}{ Sex } \\
\hline Female & 223 & 78.0 & 123 & 55.2 & 100 & 44.8 & 0.2900 \\
\hline Male & 63 & 22.0 & 30 & 47.6 & 33 & 52.4 & \\
\hline \multicolumn{8}{|c|}{ Extrathyroidal extension } \\
\hline Absent & 165 & 57.7 & 85 & 51.5 & 80 & 48.5 & 0.2488 \\
\hline Present & 111 & 42.3 & 65 & 58.6 & 46 & 41.4 & \\
\hline \multicolumn{8}{|l|}{ pT } \\
\hline $\mathrm{T} 1$ & 85 & 29.9 & 43 & 50.6 & 42 & 49.4 & 0.1013 \\
\hline $\mathrm{T} 2$ & 59 & 20.8 & 28 & 47.5 & 31 & 52.5 & \\
\hline T3 & 123 & 43.3 & 75 & 61.0 & 48 & 39.0 & \\
\hline $\mathrm{T} 4$ & 17 & 6.0 & 6 & 35.3 & 11 & 64.7 & \\
\hline \multicolumn{8}{|l|}{$\mathrm{pN}$} \\
\hline pNO & 166 & 58.7 & 82 & 49.4 & 84 & 50.6 & 0.1112 \\
\hline pN1 & 117 & 41.3 & 69 & 59.0 & 48 & 41.0 & \\
\hline \multicolumn{8}{|l|}{$\mathrm{pM}$} \\
\hline pMo & 272 & 95.4 & 151 & 55.5 & 121 & 44.5 & 0.0033 \\
\hline pM1 & 13 & 4.6 & 2 & 15.4 & 11 & 84.6 & \\
\hline \multicolumn{8}{|l|}{ Stage } \\
\hline I & 195 & 68.6 & 109 & 55.9 & 86 & 44.1 & 0.0081 \\
\hline II & 19 & 6.7 & 9 & 47.4 & 10 & 52.6 & \\
\hline III & 40 & 14.1 & 26 & 65.0 & 14 & 35.0 & \\
\hline IV & 30 & 10.6 & 8 & 26.7 & 22 & 73.3 & \\
\hline \multicolumn{8}{|l|}{ Histology type } \\
\hline Classical variant & 138 & 48.3 & 75 & 54.3 & 63 & 45.7 & 0.0006 \\
\hline Follicular variant & 59 & 20.6 & 20 & 33.9 & 39 & 66.1 & \\
\hline Tall-cell variant & 43 & 15.0 & 32 & 74.4 & 11 & 25.6 & \\
\hline Other variants & 46 & 16.1 & 26 & 56.5 & 20 & 43.5 & \\
\hline \multicolumn{8}{|l|}{ Disease-free survival } \\
\hline 5 years & & & & 81.3 & & 77.9 & 0.5197 \\
\hline
\end{tabular}

Furthermore, the carrier of this variant developed PTC at a very early age of 18 years. The early onset of PTC suggests that POLE p.Thr457Met might have strong cause-effect on pathogenesis of PTC. Interestingly, this variant was also identified in one CRC patient previously by us (45). Our data indicate that this variant might predispose to not only PTC but also CRC. However, further functional analysis is required to investigate the effect of this variant on the function of the POLE gene. In our cohort, we did not identify any germline pathogenic variants which were common in Western populations. These data imply the unique spectrum of proofreading domain pathogenic variants of POLE and POLD1 in our population. Despite the large number of cases screened, no somatic pathogenic variants were identified in our cohort, indicating that somatic proofreading domain pathogenic variants of POLE and POLD1 might not play important role in the development of sporadic PTC in our population.
We have previously studied the expression of POLE and POLD1 in endometrial carcinomas and their clinicopathological associations (34). However, to the best of our knowledge, this is the first study to report the clinicopathological associations of POLE and POLD1 protein expression in PTC. Low expression of POLD1 was associated with poorer prognostic markers such as distant metastasis and stage IV tumours. We also found low expression of POLE and POLD1 to be associated with poor prognostic factors such as lymph node involvement, grade 3 tumours and stage III tumours in CRC (45). However, no significant association with disease-free survival was noted with both biomarkers. Interestingly, while the case harbouring POLE p.Thr457Met showed a low expression of POLE protein, another case harbouring the pathogenic variant of POLD1 p. Gln336Ter showed high expression of POLD1. This discrepancy between protein expression and mutation has been highlighted previously by us (34) and others (12) in different organ sites. It might be

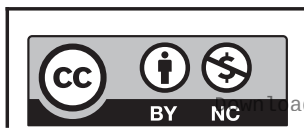

This work is licensed under a Creative Commons Attribution-NonCommercial 4.0 International License. ded from Bioscientifica.com at 04/26/2023 04:09:14AM via free access 

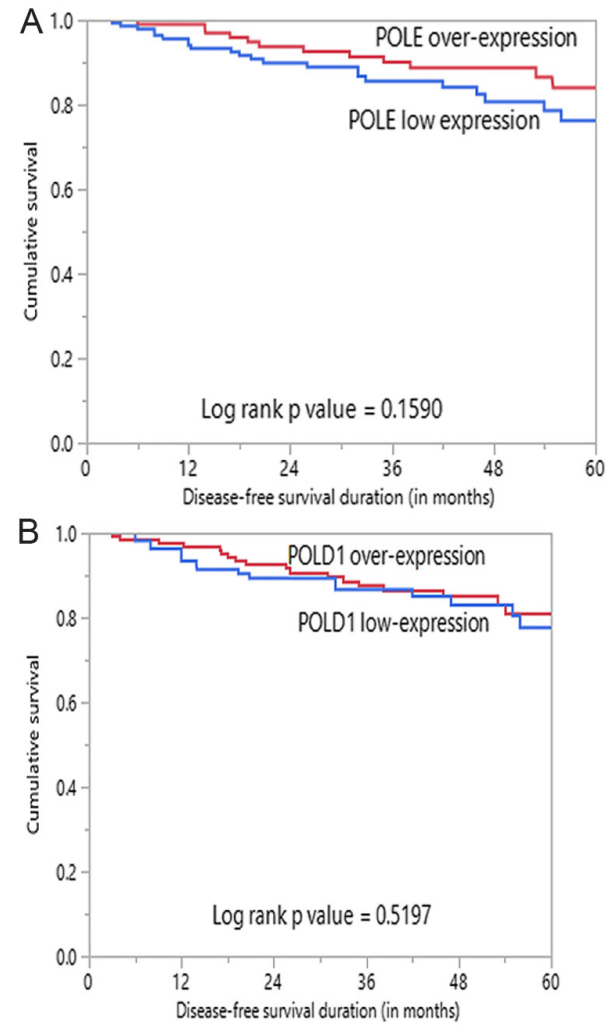

Figure 3

Kaplan-Meier survival analysis for the prognostic significance of POLE and POLD1 expression in PTC. (A) There was no significant difference in diseasefree survival with POLE expression $(P=0.1590)$. (B) There was no significant difference in disease-free survival with POLD1 expression $(P=0.5197)$.

partly explained by the fact that only pathogenic variants in proofreading region were investigated. In addition, a previous study also demonstrated that there were more truncated variants detected in the region outside of proofreading domain in POLE and POLD1 genes (46) and these truncated variants could also cause loss of POLE or POLD1 expression. Further studies are warranted to validate our findings.

\section{Conclusions}

In conclusion, this study presents data on the frequency of POLE and POLD1 proofreading domain somatic and germline pathogenic variants and association of POLE and POLD1 expression with prognostic biomarkers in a cohort of patients with PTC; more specifically, in the Middle East. Our data suggest that pathogenic variants in the proofreading domain of POLE and POLD1 is a cause of PTC and low expression of POLD1 is found to be associated with poor prognostic markers.
Nonetheless, it may be of interest to include these two genes in the gene panel for future studies.

Declaration of interest

The authors declare that there is no conflict of interest that could be perceived as prejudicing the impartiality of the research reported.

\section{Funding}

This research did not receive any specific grant from any funding agency in the public, commercial or not-for-profit sector.

\section{References}

1 Gonzalez-Gonzalez R, Bologna-Molina R, Carreon-Burciaga RG, Gomezpalacio-Gastelum M, Molina-Frechero N \& SalazarRodriguez S. Papillary thyroid carcinoma: differential diagnosis and prognostic values of its different variants: review of the literature. ISRN Oncology 20112011 915925. (https://doi. org/10.5402/2011/915925)

2 Bu R, Siraj AK, Divya SP, Kong Y, Parvathareddy SK, Al-Rasheed M, Al-Obaisi KA, Victoria IG, Al-Sobhi SS, Al-Dawish M, et al. Telomerase reverse transcriptase mutations are independent predictor of disease-free survival in Middle Eastern papillary thyroid cancer. International Journal of Cancer 2018142 2028-2039. (https://doi. org/10.1002/ijc.31225)

3 Hussain F, Iqbal S, Mehmood A, Bazarbashi S, ElHassan T \& Chaudhri N. Incidence of thyroid cancer in the Kingdom of Saudi Arabia, 2000-2010. Hematology/Oncology and Stem Cell Therapy 20136 58-64. (https://doi.org/10.1016/j.hemonc.2013.05.004)

4 Schneider DF \& Chen H. New developments in the diagnosis and treatment of thyroid cancer. CA: A Cancer Journal for Clinicians 2013 63 374-394. (https://doi.org/10.3322/caac.21195)

5 Mazzaferri EL \& Jhiang SM. Long-term impact of initial surgical and medical therapy on papillary and follicular thyroid cancer. American Journal of Medicine 199497 418-428. (https://doi.org/10.1016/00029343(94)90321-2)

6 Fonseca E, Soares P, Rossi S \& Sobrinho-Simoes M. Prognostic factors in thyroid carcinomas. Verhandlungen der Deutschen Gesellschaft für Pathologie 199781 82-96.

7 Yu Y, Dong L, Li DP, Chuai SK, Wu ZG, Zheng XQ, Cheng YA, Han L, Yu JP \& Gao M. Targeted DNA sequencing detects mutations related to susceptibility among familial non-medullary thyroid cancer. Scientific Reports 20155 16129-16141. (https://doi.org/10.1038/srep16129)

8 Capezzone M, Cantara S, Marchisotta S, Filetti S, De Santi MM, Rossi B, Ronga G, Durante C \& Pacini F. Short telomeres, telomerase reverse transcriptase gene amplification, and increased telomerase activity in the blood of familial papillary thyroid cancer patients. Journal of Clinical Endocrinology and Metabolism 200893 3950-3957. (https://doi.org/10.1210/jc.2008-0372)

9 Kunkel TA. DNA replication fidelity. Journal of Biological Chemistry 2004279 16895-16898. (https://doi.org/10.1074/jbc.R400006200)

10 Preston BD, Albertson TM \& Herr AJ. DNA replication fidelity and cancer. Seminars in Cancer Biology 201020 281-293. (https://doi. org/10.1016/j.semcancer.2010.10.009)

11 Garg P \& Burgers PMJ. DNA polymerases that propagate the eukaryotic DNA replication fork. Critical Reviews in Biochemistry and Molecular Biology 200540 115-128. (https://doi. org/10.1080/10409230590935433)

12 Elsayed FA, Kets CM, Ruano D, van den Akker B, Mensenkamp AR, Schrumpf M, Nielsen M, Wijnen JT, Tops CM, Ligtenberg MJ, 
et al. Germline variants in POLE are associated with early onset mismatch repair deficient colorectal cancer. European Journal of Human Genetics 201523 1080-1084. (https://doi.org/10.1038/ ejhg.2014.242)

13 Simon M, Giot L \& Faye GJT. 3' to 5' exonuclease activity located in the DNA polymerase delta subunit of Saccharomyces cerevisiae is required for accurate replication. EMBO Journal 199110 2165-2170. (https://doi.org/10.1002/j.1460-2075.1991.tb07751.x)

14 Albertson TM, Ogawa M, Bugni JM, Hays LE, Chen Y, Wang Y, Treuting PM, Heddle JA, Goldsby RE \& Preston BD. DNA polymerase epsilon and delta proofreading suppress discrete mutator and cancer phenotypes in mice. PNAS 2009106 17101-17104. (https://doi. org/10.1073/pnas.0907147106)

15 Venkatesan RN, Hsu JJ, Lawrence NA, Preston BD \& Loeb LA Mutator phenotypes caused by substitution at a conserved motif A residue in eukaryotic DNA polymerase delta. Journal of Biological Chemistry 2006281 4486-4494. (https://doi.org/10.1074/jbc. M510245200)

16 Goldsby RE, Lawrence NA, Hays LE, Olmsted EA, Chen X, Singh M $\&$ Preston BD. Defective DNA polymerase-delta proofreading causes cancer susceptibility in mice. Nature Medicine 20017 638-639. (https://doi.org/10.1038/88963)

17 Goldsby RE, Hays LE, Chen X, Olmsted EA, Slayton WB, Spangrude GJ \& Preston BD. High incidence of epithelial cancers in mice deficient for DNA polymerase delta proofreading. PNAS 2002 99 15560-15565. (https://doi.org/10.1073/pnas.232340999)

18 Palles C, Cazier JB, Howarth KM, Domingo E, Jones AM, Broderick P, Kemp Z, Spain SL, Guarino E, Salguero I, et al. Germline mutations affecting the proofreading domains of POLE and POLD1 predispose to colorectal adenomas and carcinomas. Nature Genetics $2013 \mathbf{4 5}$ 136-144. (https://doi.org/10.1038/ng.2503)

19 Church DN, Briggs SE, Palles C, Domingo E, Kearsey SJ, Grimes JM, Gorman M, Martin L, Howarth KM, Hodgson SV, et al. DNA polymerase epsilon and delta exonuclease domain mutations in endometrial cancer. Human Molecular Genetics 201322 2820-2828. (https://doi.org/10.1093/hmg/ddt131)

20 Church DN, Stelloo E, Nout RA, Valtcheva N, Depreeuw J, ter Haar N, Noske A, Amant F, Tomlinson IP, Wild PJ, et al. Prognostic significance of POLE proofreading mutations in endometrial cancer. Journal of the National Cancer Institute 2015107 402. (https://doi. org/10.1093/jnci/dju402)

21 Levine DA \&Cancer Genome Atlas Research Network

22 Imboden S, Nastic D, Ghaderi M, Rydberg F, Rau TT, Mueller MD, Epstein E \& Carlson JW. Phenotype of POLE-mutated endometrial cancer. PLoS ONE 201914 e0214318. (https://doi.org/10.1371/ journal.pone.0214318)

23 Mo S, Li Y \& Peng J. Somatic POLE proofreading domain mutations by next generation sequencing to predict outcomes in stage II colorectal cancer. Journal of Clinical Oncology 201937 559. (https:// doi.org/10.1200/JCO.2019.37.4_suppl.559)

24 Briggs S \& Tomlinson I. Germline and somatic polymerase $\varepsilon$ and $\delta$ mutations define a new class of hypermutated colorectal and endometrial cancers. Journal of Pathology 2013230 148-153. (https:// doi.org/10.1002/path.4185)

25 Agrawal N, Akbani R, Aksoy BA, Ally A, Arachchi H, Asa SL, Auman JT, Balasundaram M, Balu S, Baylin SB, et al. Integrated genomic characterization of papillary thyroid carcinoma. Cell 2014159 676-690. (https://doi.org/10.1016/j.cell.2014.09.050)

26 Khoo US, Ozcelik H, Cheung AN, Chow LW, Ngan HY, Done SJ, Liang AC, Chan VW, Au GK, Ng WF, et al. Somatic mutations in the BRCA1 gene in Chinese sporadic breast and ovarian cancer. Oncogene 199918 4643-4646. (https://doi.org/10.1038/sj.onc.1202847)

27 Abubaker J, Jehan Z, Bavi P, Sultana M, Al-Harbi S, Ibrahim M, Al-Nuaim A, Ahmed M, Amin T, Al-Fehaily M, et al. Clinicopathological analysis of papillary thyroid cancer with PIK3CA alterations in a Middle Eastern population. Journal of
Clinical Endocrinology and Metabolism 200893 611-618. (https://doi. org/10.1210/jc.2007-1717)

28 Siraj AK, Masoodi T, Bu R, Beg S, Al-Sobhi SS, Al-Dayel F, Al-Dawish M, Alkuraya FS \& Al-Kuraya KS. Genomic profiling of thyroid cancer reveals a role for thyroglobulin in metastasis. American Journal of Human Genetics 201698 1170-1180. (https://doi. org/10.1016/j.ajhg.2016.04.014)

29 Li H \& Durbin R. Fast and accurate long-read alignment with Burrows-Wheeler transform. Bioinformatics 201026 589-595. (https://doi.org/10.1093/bioinformatics/btp698)

30 McKenna A, Hanna M, Banks E, Sivachenko A, Cibulskis K, Kernytsky A, Garimella K, Altshuler D, Gabriel S, Daly M, et al. The genome analysis toolkit: a MapReduce framework for analyzing next-generation DNA sequencing data. Genome Research 201020 1297-1303. (https://doi.org/10.1101/gr.107524.110)

31 Wang K, Li M \& Hakonarson H. ANNOVAR: functional annotation of genetic variants from high-throughput sequencing data. Nucleic Acids Research 201038 e164. (https://doi.org/10.1093/nar/gkq603)

32 Schwarz JM, Cooper DN, Schuelke M \& Seelow D. MutationTaster2: mutation prediction for the deep-sequencing age. Nature Methods 201411 361-362. (https://doi.org/10.1038/nmeth.2890)

33 Siraj AK, Bavi P, Abubaker J, Jehan Z, Sultana M, Al-Dayel F, Al-Nuaim A, Alzahrani A, Ahmed M, Al-Sanea O, et al. Genome-wide expression analysis of Middle Eastern papillary thyroid cancer reveals c-MET as a novel target for cancer therapy. Journal of Pathology 2007213 190-199. (https://doi.org/10.1002/ path.2215)

34 Siraj AK, Parvathareddy SK, Bu R, Iqbal K, Siraj S, Masoodi T, Concepcion RM, Ghazwani LO, AlBadawi I, Al-Dayel F, et al. Germline POLE and POLD1 proofreading domain mutations in endometrial carcinoma from Middle Eastern region. Cancer Cell International 2019 19 334. (https://doi.org/10.1186/s12935-019-1058-9)

35 Camp RL, Dolled-Filhart M \& Rimm DL. X-tile: a new bio-informatics tool for biomarker assessment and outcome-based cut-point optimization. Clinical Cancer Research 200410 7252-7259. (https:// doi.org/10.1158/1078-0432.CCR-04-0713)

36 Siraj AK, Prabhakaran S, Bavi P, Bu R, Beg S, Hazmi MA, Al-Rasheed M, Al-Assiri M, Sairafi R, Al-Dayel F, et al. Prevalence of Lynch syndrome in a Middle Eastern population with colorectal cancer. Cancer 2015121 1762-1771. (https://doi.org/10.1002/ cncr.29288)

37 Buchanan DD, Stewart JR, Clendenning M, Rosty C, Mahmood K, Pope BJ, Jenkins MA, Hopper JL, Southey MC, Macrae FA, et al. Risk of colorectal cancer for carriers of a germ-line mutation in POLE or POLD1. Genetics in Medicine 201820 890-895. (https://doi. org/10.1038/gim.2017.185)

38 Vande Perre P, Siegfried A, Corsini C, Bonnet D, Toulas C, Hamzaoui N, Selves J, Chipoulet E, Hoffmann JS, Uro-Coste E, et al. Germline mutation p.N363K in POLE is associated with an increased risk of colorectal cancer and giant cell glioblastoma. Familial Cancer 201918 173-178. (https://doi.org/10.1007/s10689018-0102-6)

39 McConechy MK, Talhouk A, Leung S, Chiu D, Yang W, Senz J, Reha-Krantz LJ, Lee CH, Huntsman DG, Gilks CB, et al. Endometrial carcinomas with POLE exonuclease domain mutations have a favorable prognosis. Clinical Cancer Research 201622 2865-2873. (https://doi.org/10.1158/1078-0432.CCR-15-2233)

40 Spier I, Holzapfel S, Altmuller J, Zhao B, Horpaopan S, Vogt S, Chen S, Morak M, Raeder S, Kayser K, et al. Frequency and phenotypic spectrum of germline mutations in POLE and seven other polymerase genes in 266 patients with colorectal adenomas and carcinomas. International Journal of Cancer 2015137 320-331. (https://doi.org/10.1002/ijc.29396)

41 Bellido F, Pineda M, Aiza G, Valdes-Mas R, Navarro M, Puente DA, Pons T, Gonzalez S, Iglesias S, Darder E, et al. POLE and POLD1 mutations in 529 kindred with familial colorectal cancer and/or

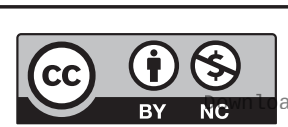

This work is licensed under a Creative Commons Attribution-NonCommercial 4.0 International License. ded from Bioscientifica.com at 04/26/2023 04:09:14AM 
polyposis: review of reported cases and recommendations for genetic testing and surveillance. Genetics in Medicine 201618 325-332. (https://doi.org/10.1038/gim.2015.75)

42 Guerra J, Pinto C, Pinto D, Pinheiro M, Silva R, Peixoto A, Rocha P, Veiga I, Santos C, Santos R, et al. POLE somatic mutations in advanced colorectal cancer. Cancer Medicine 20176 2966-2971. (https://doi.org/10.1002/cam4.1245)

43 Rizvi NA, Hellmann MD, Snyder A, Kvistborg P, Makarov V, Havel JJ, Lee W, Yuan J, Wong P, Ho TS, et al. Cancer immunology. Mutational landscape determines sensitivity to PD-1 blockade in non-small cell lung cancer. Science 2015348 124-128. (https://doi.org/10.1126/ science.aaa1348)

44 Bouffet E, Larouche V, Campbell BB, Merico D, de Borja R, Aronson M, Durno C, Krueger J, Cabric V, Ramaswamy V, et al.
Immune checkpoint inhibition for hypermutant glioblastoma multiforme resulting from germline biallelic mismatch repair deficiency. Journal of Clinical Oncology 201634 2206-2211. (https:// doi.org/10.1200/JCO.2016.66.6552)

45 Siraj AK, Bu R, Iqbal K, Parvathareddy SK, Masoodi T, Siraj N, Al-Rasheed M, Kong Y, Ahmed SO, Al-Obaisi KAS, et al. POLE and POLD1 germline exonuclease domain pathogenic variants, a rare event in colorectal cancer from the Middle East. Molecular Genetics and Genomic Medicine 20208 e1368. (https://doi.org/10.1002/ mgg3.1368)

46 Campbell BB, Light N, Fabrizio D, Zatzman M, Fuligni F, de Borja R, Davidson S, Edwards M, Elvin JA, Hodel KP, et al. Comprehensive analysis of hypermutation in human Cancer. Cell 2017171 1042-1056.e10. (https://doi.org/10.1016/j.cell.2017.09.048)

Received in final form 13 August 2020

Accepted 25 August 2020

Accepted Manuscript published online 26 August 2020
This work is licensed under a Creative Commons Attribution-NonCommercial 4.0 International License. ded from Bioscientifica.com at 04/26/2023 04:09:14AM via free access 